\title{
Anti-inflammation and anti-apoptosis effects of growth arrest-specific protein 6 in acute liver injury induced by LPS/D-GaIN in mice ${ }^{1}$
}

\author{
Qian Wang' (D) , Yang Zhao" (D) , Bin Zang'II' (D)
}

' Master, Department of Emergency Medicine, 4th Affiliated Hospital of China Medical University. Student, Department of Critical Care Medicine, Shengjing Hospital, China Medical University, Shenyang, China. Technical procedures, interpretation of data, statistical analysis, manuscript preparation..

" MD, Department of Critical Care Medicine, Shengjing Hospital of China Medical University, Shenyang, China. Acquisition and interpretation of data, statistical analysis, critical revision.

"I'Master, Chairman and Head, Department of Critical Care Medicine, Shengjing Hospital of China Medical University, Shenyang, China. Conception and design of the study, critical revision, supervised all phases of the study.

\begin{abstract}
Purpose: To investigate the effect of growth arrest-specific protein 6 (Gas6) on acute liver injury in mice and related mechanisms.

Methods: Thirty C57BL/6 (6-8 weeks old) mice were randomly divided into control, LPS/D-GalN, and LPS/D-GalN+Gas6 groups (10 mice in each group). The LPS/D-GaIN group was intraperitoneally administered with LPS $(0.25 \mathrm{mg} / \mathrm{Kg}$ ) and D-GalN (400 mg/Kg) for $5 \mathrm{~h}$. The LPS/D-GalN+Gas6 group was intraperitoneally administered with rmGas 6 one hour before intraperitoneal application of LPS/D-GalN. All subjects were sacrificed at $5 \mathrm{~h}$ for blood and tissue analysis. The expression of protein and mRNA was assessed by western blotting and RT-PCR, respectively.
\end{abstract}

Results: Compared with the control group, AST, ALT, IL-1 $\beta$, TNF- $\alpha$, IL-6 IL-10, MPO activity were increased in the LPS/D-GaIN group. However, they were significantly inhibited by Gas6. Gas6 markedly suppressed the expression of apoptosis-related protein induced by LPS/D-GalN. Moreover, Gas6 attenuated the activation of the NF-KB signaling pathway in acute liver injury induced by LPS/D-GaIN.

Conclusions: Gas6 alleviates acute liver injury in mice through regulating NF-KB signaling pathways. Gas6 can be a potential therapeutic agent in treating LPS/D-GaIN-induced acute liver injury in the future.

Key words: Chemical and Drug Induced Liver Injury. Sepsis. Mice. 


\section{- Introduction}

Sepsis is a life-threatening condition caused by a dysfunctional response to infection and is the leading cause of death in the intensive care unit (ICU) ${ }^{1}$. Sepsis is a significant public health problem due to its high morbidity and mortality rates, which are associated with hemodynamic damage, multiple organ dysfunction, and unconstrained inflammation ${ }^{2,3}$. In the course of sepsis, the liver may be a potential target for dysregulation of the inflammatory response ${ }^{4}$.

Although the clinical treatment of sepsis has progressed, its morbidity and mortality are still high ${ }^{5}$. Hepatic dysfunction has specific prognostic relevance to the course of sepsis and is a powerful independent predictor of mortality. Improving liver function can reduce morbidity and mortality in patients with sepsis. It is a major challenge to discover effective and safe therapy of sepsisinduced acute liver injury. Currently, few studies have led to substantial advances in drug development or therapy. Therefore, there is an urgent need for a safe and effective treatment strategy for acute liver injury caused by sepsis.

Growth arrest-specific protein 6 (Gas6) and its tyrosine kinase TAM receptors (Tyro3, Axl, and Mer) are involved in growth and survival processes during tissue repair and development ${ }^{6}$. In the liver, Gas 6 is mainly expressed in Kupffer cells ${ }^{7}$, and the expression of Gas6 is related to the severity of the disease in patients with septic shock, especially with kidney and liver dysfunction. Gas6 is a vitamin K-dependent protein with many functions. Although Gas6 and protein S have common characteristics, their biological effects are significantly different. Gas6 rarely participates in the coagulation cascade. It is mainly involved in cell protection and tissue formation and has extensive inhibition of inflammation.

Numerous studies have shown that gas 6 can improve antioxidant capacity and inhibit inflammatory responses. Most previous studies have focused on ischemiareperfusion models ${ }^{8}$. Few studies have systematically reviewed the protection of gas6 against LPS/D-GalNinduced acute liver injury. We designed the study of Gas6 on acute liver injury to reveal its hepatoprotective effect and underlying mechanisms.

\section{- Methods}

\section{Chemicals}

LPS, D-galactosamine were purchased from SigmaAldrich Co (St. Louis, MO, USA). AST, ALT, MPO kits were purchased from the Institute of Jiancheng Bioengineering (Nanjing, China). TNF- $\alpha$, IL-1 $\beta$, and IL-6 ELISA kits were purchased from Biolegend (San Diego, CA, USA). Gas6 was purchased from R\&D Systems (Minneapolis, MN, USA). Antibodies used for western blot were as follows: anti-Bcl-2 (Proteintech, Rosemont, IL, USA), anti-Bax (Proteintech, Rosemont, IL, USA), anti-ß-actin (Proteintech, Rosemont, IL, USA), NF-KB signal pathway kit (Cell Signaling Technology, Beverly, MA, USA).

\section{Animals and treatment}

6-8 weeks male C57BL/6 mice were purchased from the Experimental Animal Center of China Medical University. Mice were housed in a specific-pathogen-free facility under $12 \mathrm{~h}$ light-dark cycle. All animals' procedures were performed according to protocols approved by the Institutional Animal Care and Use Committee of China Medical University (Grant No. 2019PS563K).

C57BL/6 mice were randomly divided into control, LPS/D-GalN, and LPS/D-GalN+Gas6 group, 10 mice in each group. The LPS/D-GalN group was intraperitoneally administered with LPS $(0.25 \mathrm{mg} / \mathrm{Kg})$ and D-GalN (400 mg/Kg). LPS/D-GalN+Gas6 group was intraperitoneally administered with rmGas6 (250 ug/Kg) one hour before intraperitoneal administration of LPS $(0.25 \mathrm{mg} / \mathrm{Kg})$ and D-GalN $(400 \mathrm{mg} / \mathrm{Kg})$. After 5 hours of LPS/D-GalN injection, mice were sacrificed under anesthesia for experimental evaluation. Blood was collected from the abdominal aorta, and the liver was dissected. The protein and total RNA were extracted immediately from the liver and frozen at $-80^{\circ} \mathrm{C}$.

\section{ALT/AST activities and inflammatory cytokines}

Blood samples were collected and centrifugated at $5000 \mathrm{rpm}$ for $10 \mathrm{~min}$. Serum aspartate aminotransferase (AST and ALT) activities were analyzed by using the commercial kits (Jiancheng Bioengineering Institute, Nanjing, China) following the instructions by the manufacturer.

Blood samples were collected for the detection of TNF- $\alpha$, IL-1 $\beta$, IL-10, and IL-6 levels using commercial kits produced by Biolegend (San Diego, CA, USA), following the instructions of the manufacturer. The concentrations of inflammatory cytokines were calculated by generating a standard curve.

\section{MPO assay}

Neutrophils are the core cells of oxidative stress, which release reactive oxygen species (ROS) and increase oxidative stress. Tissue myeloperoxidase activity can be used as an indicator of neutrophil infiltration. $5 \mathrm{~h}$ after administration of LPS/D-GalN, liver tissue was homogenized in PBS solution (20 mmol/L, $\mathrm{pH} 7.4)$ and 
centrifuged at $30,000 \mathrm{~g}$ for 30 minutes. The precipitate was redissolved in potassium phosphate buffer $(50 \mathrm{mmol} / \mathrm{L}, \mathrm{pH}$ 6.0) with $0.5 \%$ hexadecyltrimethylammonium bromide. The supernatant was taken after centrifugation at 20,000 $\mathrm{g}$ for $15 \mathrm{~min}$. MPO activity in the liver was determined by absorbance change at $460 \mathrm{~nm}$ with spectrophotometric.

\section{Western blotting}

The liver tissue was taken to extract total and nuclear proteins by commercially kits (Beyotime, China) according to the manufacturer's instructions and denatured with $5 \times$ loading buffer at $95^{\circ} \mathrm{C}$ for $5 \mathrm{~min}$. After the protein concentration was determined by BCA protein estimation kit (Beyotime, China), the sample was diluted to the same concentration. Equal quantities of protein samples were fractionated by SDS-PAGE and then transferred to the PVDF membrane. The membranes were overnight incubated with primary antibodies against Bcl-2 (1: 1000), Bax (1: 1000), ІкB $\alpha$ (1: 1000), NF-KB (1: 1000), p-NF-KB (1: 1000), $\beta$-actin (1:1000). The secondary antibody (1: 2000) was incubated for 2 $\mathrm{h}$ at room temperature. A chemiluminescent peroxidase substrate (ECL; Beyotime, China) was applied according to the manufacturer's instructions.

\section{Quantitative real-time PCR}

Total RNA from the mouse's liver was isolated with RNAiso Plus (TaKaRa, Dalian, China) and reverse-transcribed into complementary DNA by using a PrimeScriptTM RT reagent Kit (TaKaRa, Dalian, China). SYBR Premix Ex Taq (TaKaRa, Dalian, China) was used to perform the PCR reaction following the instructions of the manufacturer. The primer sequences were as follows: Bax Forward: ATGCGTCCACCAAGAAGC, Reverse: CAGTTGAAGTTGCCATCAGC. Bcl-2 Forward: AGCCTGAGAGCAACCCAAT, Reverse: AGCGACGAGAGAAGTCATCC. $\beta$-actin Forward: CGTGAAAAGATGACCCAGATCA, Reverse: TGGTACGACCAGAGGCATACAG. Quantitative real-time PCR was performed using the Applied Biosystems 7500 Real-Time System. The comparative CT method (2- $\Delta \Delta \mathrm{Ct}$ ) was used to determine the relative quantification of target genes normalized to that of $\beta$-actin.

\section{Statistical analysis}

The data are expressed as the means \pm SE at least three independent experiments and compared by the one-way analysis of variance (ANOVA) and the Student Newman-Keuls test using the Prism 7 software. P-values less than 0.05 were considered as statistically significant.

\section{- Results}

\section{Gas6 attenuates AST and ALT activity induced by LPS/D-GaIN}

Serum AST and ALT were assessed to observe the effect of Gas6 on LPS/D-GalN-induced liver injury. As shown in Figure 1, the ALT and AST activities of the LPS/ D-GalN group were increased dramatically. However, Gas6 significantly inhibits AST and ALT activity in liver injury induced by LPS/D-GalN $(p<0.01)$.

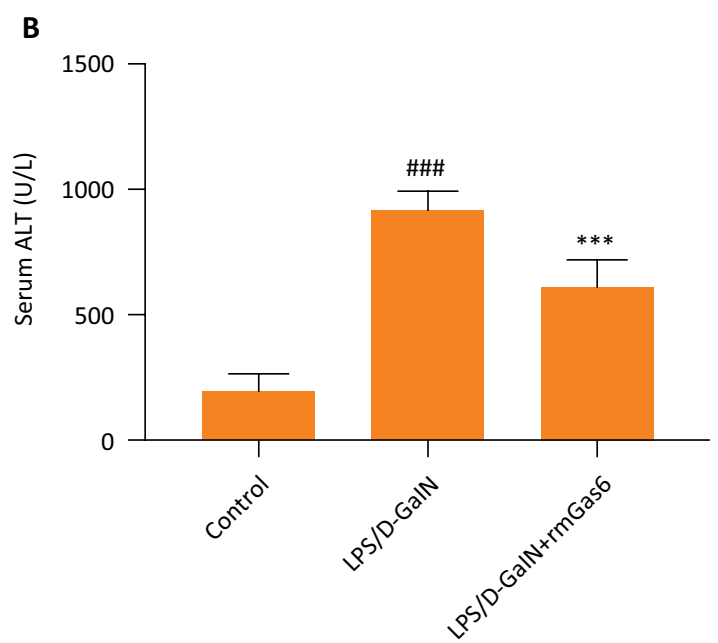

Figure 1 - Gas6 repressed the activities of ALT and AST in acute liver injury induced by LPS/D-GalN. ALT and AST activities were evaluated by using commercial assay kit according to the manufacturer's protocols. ${ }^{* * *} p<0.01$ compared to LPS/D-GalN group. \#\#\# $p<0.01$ compared to control group. 


\section{Gas6 significantly reduces the production of} inflammatory cytokine induced by LPS/D-GaIN

The prominent manifestation of sepsis is an excessive inflammatory response to infection. We measured serum inflammatory cytokine, including TNF- $\alpha$, IL-1 $\beta$,
IL-10, and IL- 6 at 5 hours after administration of LPS/DGalN. The LPS/D-GalN group had significantly increased levels of TNF- $\alpha, \mathrm{IL}-1 \beta, \mathrm{IL}-10$, and IL- 6 , whereas Gas 6 inhibited the overproduction of these inflammatory cytokines (Fig. $2, p<0.01$ ).
A

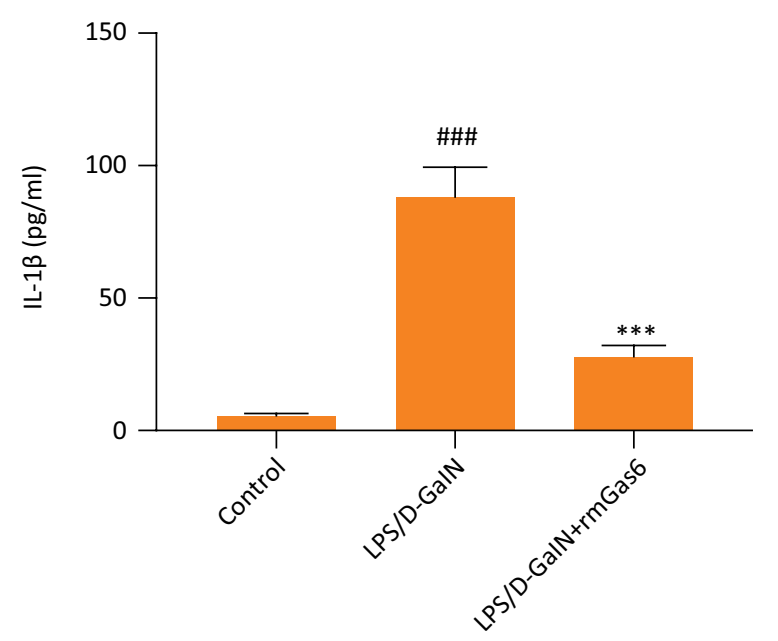

C

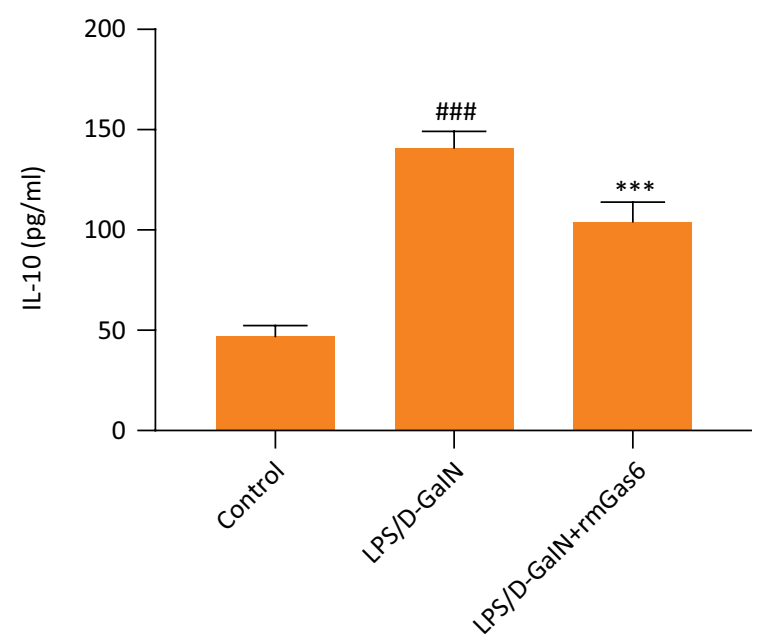

B

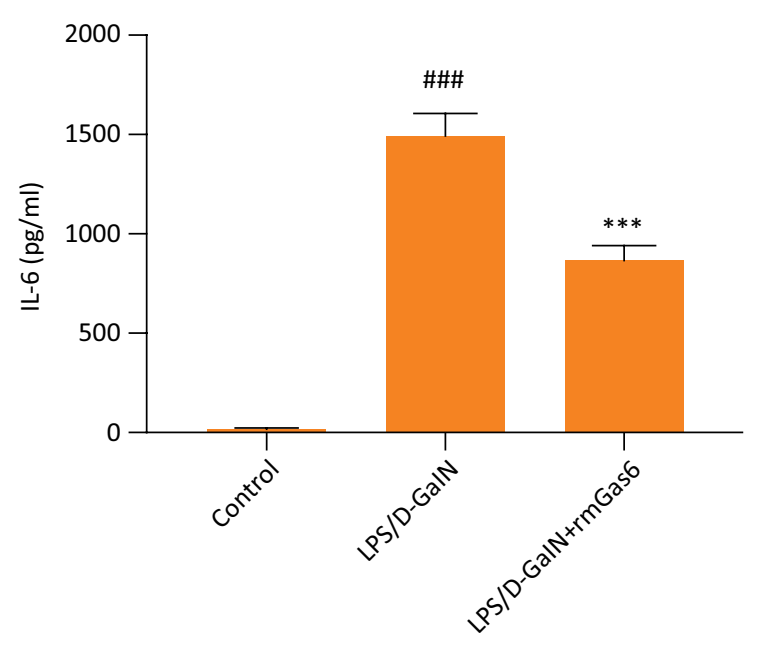

D

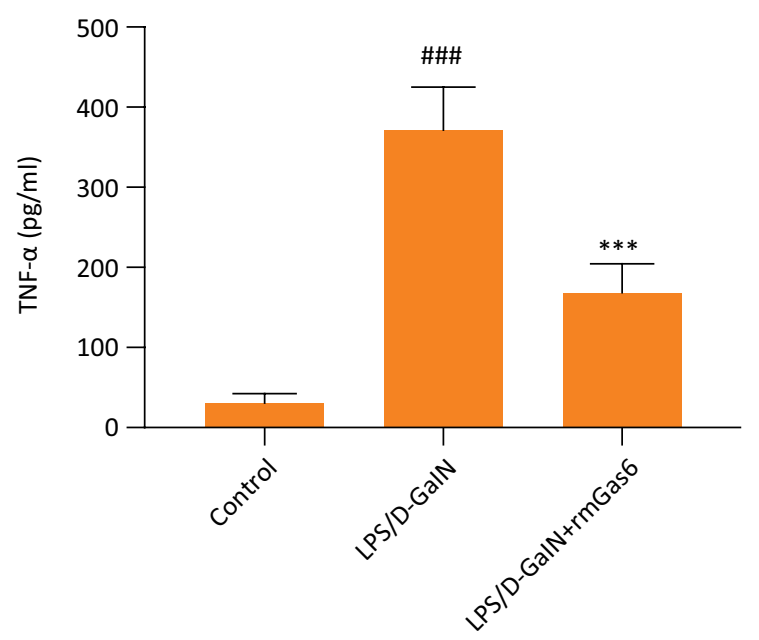

Figure 2 - Effect of Gas6 on IL-1ß (A), IL-6 (B), IL-10 (C), and TNF- $\alpha$ (D). Quantitation of IL-1ß, IL-6, IL-10, and TNF- $\alpha$ were performed by ELISA. Data are represented as mean $\pm \mathrm{SE}(\mathrm{n}=10)$. ${ }^{* * *} p<0.01$ compared to LPS/D-GalN group. \#\#\# $p<$ 0.01 compared to control group.

\section{Gas6 inhibits activation of MPO induced by LPS/D-GaIN}

Tissue myeloperoxidase activity can be used as an indicator of neutrophil infiltration, which releases reactive oxygen species (ROS) and causes oxidative stress. As shown in Figure 3, the MPO activities of the LPS/D-GalN group were increased dramatically. However, Gas6 significantly inhibits MPO activity in liver injury induced by LPS/D-GaIN $(p<0.01)$. 


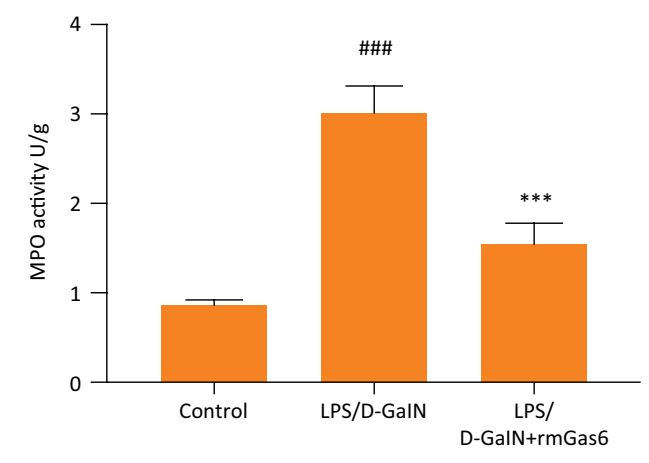

Figure 3 - Effect of Gas6 on LPS/D-GalN-induced liver injury. Leukocyte infiltration was evaluated by using MPO assay kit according to the manufacturer's protocols. ${ }^{* *} p<0.01$ compared to LPS/D-GalN group. \#\#\# $p<0.01$ compared to control group.

A

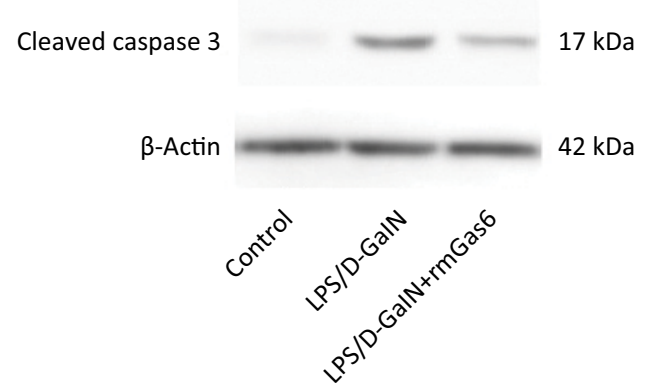

C

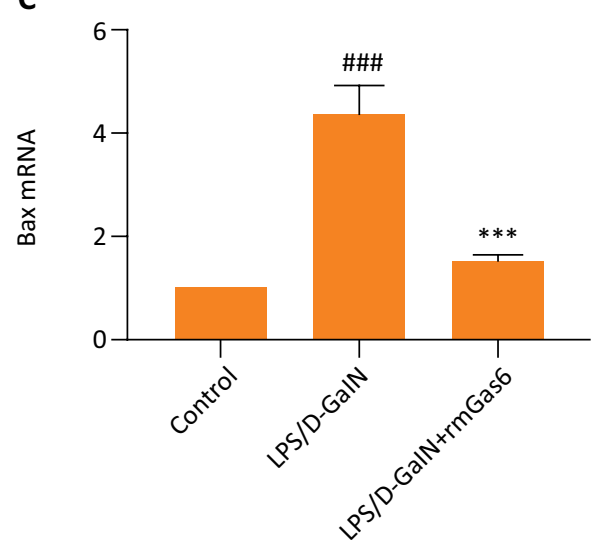

\section{Gas6 inhibits the expression of proteins induced by LPS/D-GaIN}

To explore the effect of Gas6 on LPS/D-GalNinduced hepatocyte apoptosis, relevant proteins (Caspase-3, Bax, and $\mathrm{Bcl}-2$ ) were examined by western blot. As shown in Figure 4, Bax increased, and $\mathrm{Bcl}-2$ expression decreased in the LPS/D-GalN group. Downregulation of $\mathrm{Bax}$ and upregulation of $\mathrm{Bcl}-2$ were found in the LPS/D-GalN +Gas6 group (Fig. 4 B-D). Furthermore, caspase-3 was elevated at $5 \mathrm{~h}$ after administration of LPS/D-GaIN. However, the increase of caspase-3 was also repressed in Gas6 pretreated group (Fig. 4A).

B

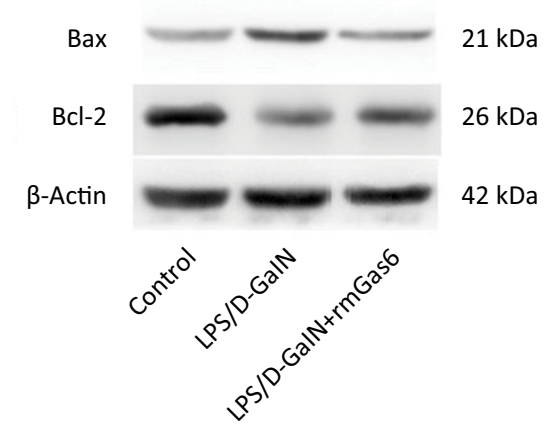

D

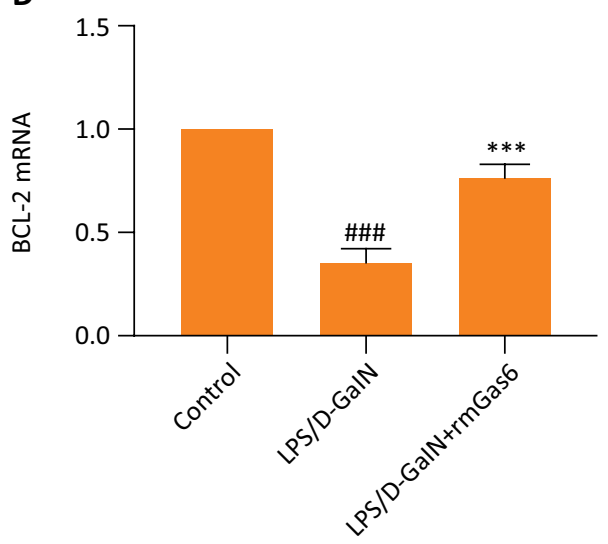

Figure 4 - Gas6 inhibited the apoptosis of the liver. Western blot and RT-PCR to determine the effect of Gas6 on apoptosisrelated proteins. (A, B) Western blot of cleaved caspase 3, Bax and Bcl-2 in different groups. (C, D) RT-PCR of Bcl-2 and Bax in different groups. $* * * p<0.01$ compared to LPS/D-GalN group. \#\#\# $p<0.01$ compared to control group.

\section{Gas6 inhibits activation of the NF-KB signaling} pathway induced by LPS/D-GaIN

Western blot analysis of critical molecules in the NF-KB pathway. As shown in Figure 5, in the LPS /
D-GalN group, expression of $\mathrm{p}-\mathrm{I} \mathrm{KB} \alpha, \mathrm{p}-\mathrm{p} 65$, and NF-kB in the nucleus were significantly increased in the CLP and CLP+PBS groups. However, Gas6 can reduce the activation of the NF-KB signal transduction pathway. 
A

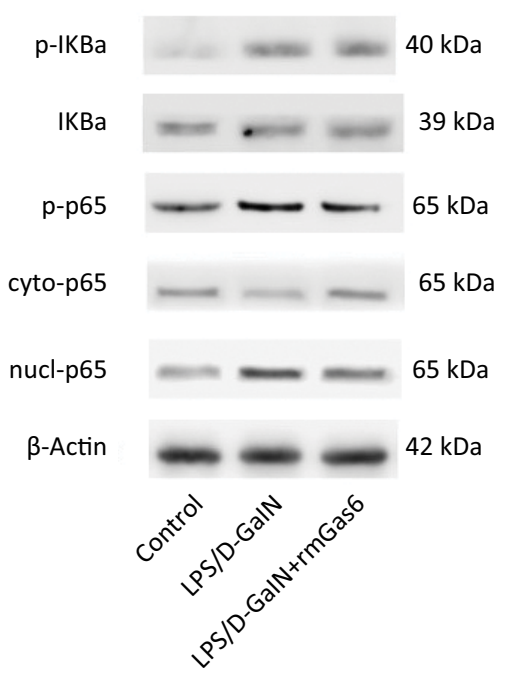

C

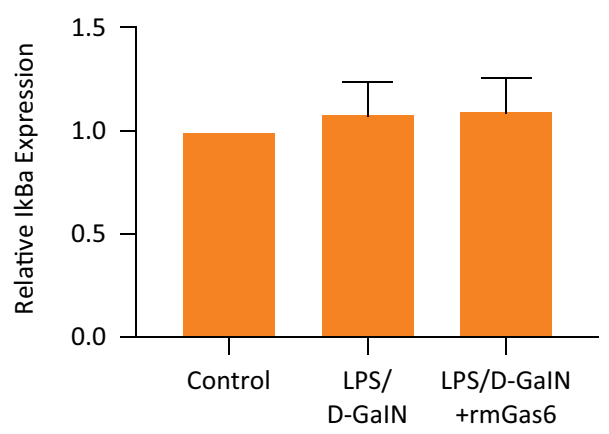

E

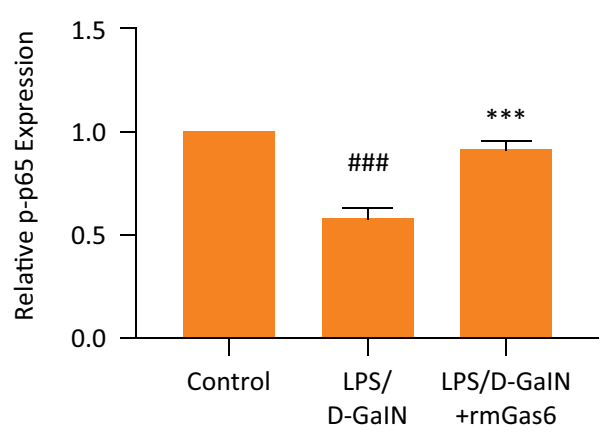

B

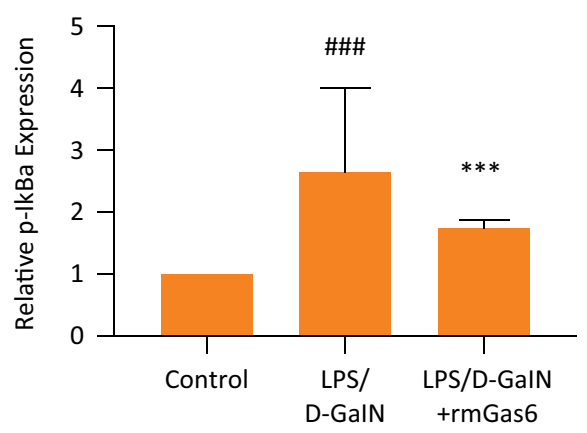

D
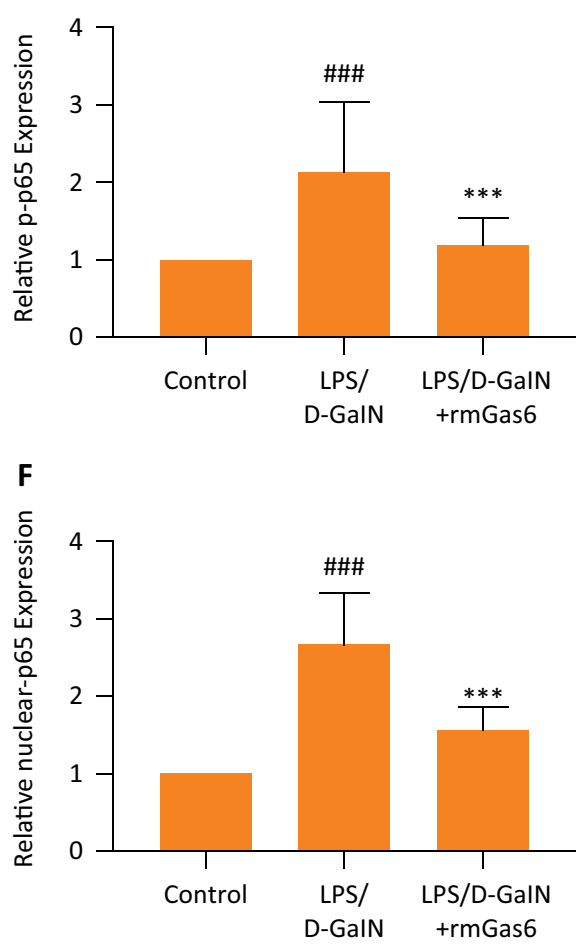

Figure 5 - Gas6 inhibited the activation of NF-KB induced by LPS/D-GalN. The expression of related proteins of the NF-KB signaling pathway were detected by western blot. The results shown are representative of at least three independent experiments. ${ }^{* * *} p<0.01$ compared to LPS/D-GalN group. \#\#\# $p<0.01$ compared to control group.

\section{- Discussion}

Gas6 is a vitamin K-dependent secreted protein consisting of 678 amino acids with a relative molecular mass of $75 \mathrm{kDa}$ and has $43 \%$ of the same sequence with protein $\mathrm{S}^{9}$. It is a common ligand for Tyro3, Axl, and Mer ${ }^{10-12}$. Gas6 and its receptors are expressed in macrophages, granulocytes, dendritic cells, and endothelial cells and vascular smooth muscle. Gas6 works by stimulating phagocytosis, reducing the inflammatory response, limiting hypoxic cell damage, and enhancing cell proliferation ${ }^{13-21}$. Gas6 activation of the TAM receptor produces meaningful therapeutic targets in thromboembolic diseases, atherosclerosis, sepsis, autoimmune diseases, and cancer ${ }^{22,23}$. 
Sepsis is a dysregulated host response caused by an infection and often affects multiple organs, such as the liver. The impact in the clinical setting is significant ${ }^{24}$. There is an urgent need to study and use novel mechanisms to avoid organ damage from sepsis ${ }^{25}$. LPS/ D-GalN induced acute liver injury is a widely accepted experimental model that closely resembles acute liver injury seen clinically ${ }^{26}$. In this in vivo model, LPS/DGalN activates a complex inflammatory response. ALT and AST are abundant in liver cells. They are a sensitive and specific marker of liver injury ${ }^{27}$. Intraperitoneal administered with LPS $(0.25 \mathrm{mg} / \mathrm{Kg})$ and D-GalN (400 $\mathrm{mg} / \mathrm{Kg}$ ) for $5 \mathrm{~h}$ markedly increased serum levels of ALT and AST confirming that acute liver injury occurred. By using a mouse model treated with LPS/D-GalN, we demonstrated that pretreatment with Gas6 could protect against liver injury. Gas6 pretreatment can reduce clinical parameters of liver function (AST and ALT), apoptosis-related proteins, inflammatory cytokines.

Inflammatory cell infiltration has shown to be involved in LPS / D-GalN-induced acute liver injury. In our study, MPO activity was used to measure neutrophil infiltration, and we found that Gas6 treatment reduced inflammatory infiltration compared with that in LPS/DGalN group. Similarly, the level of a direct indicator of the inflammatory response was also significantly reduced by the administration of Gas6. In our study, Gas6 treatment also showed a noticeable effect of preventing the overproduction of IL-1, IL-6, TNF-a, IL-10. In the meanwhile, we also noted a significant decrease of apoptotic protein in the liver after LPS/D-GalN with Gas6 treatment. The important role of Gas6 is to enhance macrophages to clear apoptotic cells. Failure to effectively clear apoptotic cells will develop secondary necrosis, which will lead to the occurrence of the inflammatory response and further tissue damage. Therefore, reducing liver cell apoptosis may be one of the mechanisms for exogenous supplementation of Gas6 to reduce LPS / D-GalNinduced liver injury.

We selected the NF-KB signaling pathway as the potential anti-inflammatory mechanism of Gas6 on LPS / D-GalN-induced acute liver injury. NF-KB activation is the key to the excessive inflammatory response that causes sepsis-related organ dysfunction ${ }^{28,29}$. P65 is an important subunit of NF-kB. The activation level of p65 is often used to indicate the degree of activation of NF$\mathrm{KB}^{30}$. LPS triggers the activation of NF-KB translocated into the nucleus, resulting in the expression of proinflammatory cytokines, such as IL-1 $1 \beta, \mathrm{IL}-6, \mathrm{TNF}-\alpha$. The released cytokines can also activate NF-KB in turn, forming a positive feedback loop. In the present study, the NF-KB signal pathway was activated by LPS/D-GalN. The phosphorylation of $p-65$ was downregulated after
Gas6 treatment. NF-kB regulates the expression of multiple genes in the early inflammatory response, and these genes are involved in the inflammatory response and the occurrence of acute liver injury. Our study found that Gas6 inhibits the activation of the NF-KB signaling pathway caused by LPS / D-GalN. Based on the above findings, the protective effect of Gas6 on LPS / D-GalNinduced acute liver injury in mice may be related to inhibition of the NF-kB signaling pathway.

\section{- Conclusions}

Gas6 can alleviate liver injury in mice. A possible mechanism is that Gas6 inhibits the activation of the NF-kB signaling pathway. This study provides a basis for elucidating the protective mechanism of Gas6 against acute liver injury.

\section{- References}

1. Pool R, Gomez H, Kellum JA. Mechanisms of Organ Dysfunction in Sepsis. Crit Care Clin. 2018;34(1):63-80. doi: 10.1016/j.ccc.2017.08.003.

2. Cecconi M, Evans L, Levy $M$, Rhodes $A$. Sepsis and septic shock. Lancet. 2018;392(10141):75-87. doi: 10.1016/ s0140-6736(18)30696-2.

3. Hotchkiss RS, Moldawer LL, Opal SM, Reinhart K, Turnbull IR, Vincent JL. Sepsis and septic shock. Nat Rev Dis Primers. 2016;2:16045. doi: 10.1038/nrdp.2016.45.

4. Woznica EA, Inglot M, Woznica RK, Lysenko L. Liver dysfunction in sepsis. Adv Clin Exp Med. 2018;27(4):54751. doi: $10.17219 /$ acem/68363.

5. Singer $M$, Deutschman CS, Seymour CW, Shankar-Hari M, Annane D, Bauer M, Bellomo R, Bernard GR, Chiche JD, Coopersmith CM, Hotchkiss RS, Levy MM, Marshall JC, Martin GS, Opal SM, Rubenfeld GD, van der Poll T, Vincent JL, Angus DC. The third international consensus definitions for sepsis and septic shock (Sepsis-3). JAMA. 2016;315(8):801-10. doi: 10.1001/jama.2016.0287.

6. Law LA, Graham DK, Di Paola J, Branchford BR. GAS6/TAM pathway signaling in hemostasis and thrombosis. Front Med. 2018;5:137. doi: 10.3389/fmed.2018.00137.

7. Lafdil F, Chobert MN, Deveaux V, Zafrani ES, Mavier P, Nakano T, Laperche $Y$, Brouillet A. Growth arrest-specific protein 6 deficiency impairs liver tissue repair after acute toxic hepatitis in mice. J Hepatol. 2009;51(1):55-66. doi: 10.1016/j.jhep.2009.02.030.

8. Lafdil F, Chobert MN, Couchie D, Brouillet A, Zafrani ES, Mavier P, Laperche Y. Induction of Gas6 protein in $\mathrm{CCl} 4$ induced rat liver injury and anti-apoptotic effect on hepatic stellate cells. Hepatology. 2006;44(1):228-39. doi: 10.1002/hep.21237.

9. Deng T, Chen $Q$, Han D. The roles of TAM receptor tyrosine kinases in the mammalian testis and immunoprivileged sites. Front Biosci (Landmark Ed). 2016;21:316-27. doi: $10.2741 / 4390$. 
10. van der Meer JH, van der Poll T, van ' $t$ Veer C. TAM receptors, Gas6, and protein S: roles in inflammation and hemostasis. Blood. 2014;123(16):2460-9. doi: 10.1182/ blood-2013-09-528752.

11. Wu G, Ma Z, Hu W, Wang D, Gong B, Fan C, Jiang S, Li T, Gao J, Yang Y. Molecular insights of Gas6/TAM in cancer development and therapy. Cell Death Dis. 2017;8(3):e2700. doi: 10.1038/cddis.2017.113.

12. Wu KS, Hung YJ, Lee $\mathrm{CH}$, Hsiao FC, Hsieh PS. The Involvement of GAS6 signaling in the development of obesity and associated inflammation. Int J Endocrinol. 2015;2015:202513. doi: 10.1155/2015/202513.

13. Zhao YF, Xu DC, Zhu GF, Zhu MY, Tang K, Li WM, Xu YW. Growth arrest-specific 6 exacerbates pressure overload-induced cardiac hypertrophy. Hypertension. 2016;67(1):118-29. doi: 10.1161/hypertensionaha.115.06254.

14. Zhao R, Li Y, Dai W. Serum sex hormone and growth arrestspecific protein 6 levels in male patients with coronary heart disease. Asian J Androl. 2016;18(4):644-9. doi: 10.4103/1008-682X.172825.

15. Wang $C$, Jin $H$, Wang $N$, Fan $S$, Wang $Y$, Zhang $Y$, Wei L, Tao X, Gu D, Zhao F, Fang J, Yao M, Qin W. Gas6/Axl Axis Contributes to chemoresistance and metastasis in breast cancer through Akt/GSK-3beta/beta-catenin signaling. Theranostics. 2016;6(8):1205-19. doi: 10.7150/ thno.15083.

16. Tsai WB, Long Y, Park JR, Chang JT, Liu H, Rodriguez-Canales J, Savaraj N, Feun LG, Davies MA, Wistuba, II, Kuo MT. Gas6/Axl is the sensor of arginine-auxotrophic response in targeted chemotherapy with arginine-depleting agents. Oncogene. 2016;35(13):1632-42. doi: 10.1038/ onc.2015.237.

17. Torii T, Yamauchi J. Gas6-Tyro3 signaling is required for Schwann cell myelination and possible remyelination. Neural Regen Res. 2016;11(2):215-6. doi: 10.4103/16735374.177714.

18. Tian W, Wang L, Yuan L, Duan W, Zhao W, Wang S, Zhang Q. A Prognostic risk model for patients with triple negative breast cancer based on stromal natural killer cells, tumorassociated macrophages and growth-arrest specific protein 6. Cancer Sci. 2016;107(7):882-9. doi: 10.1111/cas.12964.

19. Szulc P. Abdominal aortic calcification: a reappraisal of epidemiological and pathophysiological data. Bone. 2016;84:25-37. doi: 10.1016/j.bone.2015.12.004.
20. Hafizi S, Gustafsson A, Stenhoff J, Dahlback B. The Ran binding protein RanBPM interacts with $A x l$ and Sky receptor tyrosine kinases. Int. J Biochem Cell Biol. 2005;37(11):234456. doi: 10.1016/j.biocel.2005.05.006.

21. Ji R, Meng L, Li Q, Lu Q. TAM receptor deficiency affects adult hippocampal neurogenesis. Metabolic Brain Dis. 2015;30(3):633-44. doi: 10.1007/s11011-014-9636-y.

22. Qin J, Li L, Zhang D, Yu H, Tan H, Zhang J, Deng B, Kijlstra $A$, Yang P. Analysis of receptor tyrosine kinase genetics identifies two novel risk loci in GAS6 and PROS1 in Behcet's disease. Sci Rep. 2016;6:26662. doi: 10.1038/srep26662.

23. Fourgeaud L, Traves PG, Tufail $Y$, Leal-Bailey $H$, Lew ED, Burrola PG, Callaway P, Zagorska A, Rothlin CV, Nimmerjahn $A$, Lemke $G$. TAM receptors regulate multiple features of microglial physiology. Nature. 2016;532(7598):240-4. doi: 10.1038/nature17630.

24. Yan J, LiS, LiS. The role of the liver in sepsis. Int Rev Immunol. 2014;33(6):498-510. doi: 10.3109/08830185.2014.889129.

25. Rossaint J, Zarbock A. Pathogenesis of multiple organ failure in sepsis. Crit Rev Immunol. 2015;35(4):277-91. doi: 10.1615/critrevimmunol.2015015461.

26. Kosai K, Matsumoto K, Funakoshi H, Nakamura T. Hepatocyte growth factor prevents endotoxin-induced lethal hepatic failure in mice. Hepatology. 1999;30(1):1519. doi: 10.1002/hep.510300102.

27. Jia YN, Lu HP, Peng YL, Zhang BS, Gong XB, Su J, Zhou Y, Pan MH, Xu L. Oxyresveratrol prevents lipopolysaccharide/ d-galactosamine-induced acute liver injury in mice. Int Immunopharmacol. 2018;56:105-12. doi: 10.1016/j. intimp.2018.01.014.

28. Zhao Y, Wang Q, Zang B. Milk fat globule-epidermal growth factor 8 (MFG-E8) attenuates sepsis-induced acute kidney injury by inhibiting NF-kappaB signaling pathway1. Acta Cir Bras. 2019;34(2):e201900209. doi: 10.1590/s01028650201900209.

29. Llacuna L, Barcena C, Bellido-Martin L, Fernandez L, Stefanovic M, Mari M, Garcia-Ruiz C, Fernandez-Checa JC, Garcia de Frutos P, Morales A. Growth arrest-specific protein 6 is hepatoprotective against murine ischemia/ reperfusion injury. Hepatology. 2010;52(4):1371-9. doi: 10.1002/hep.23833.

30. Sanz AB, Sanchez-Nino MD, Ramos AM, Moreno JA, Santamaria B, Ruiz-Ortega M, Egido J, Ortiz A. NF-kappaB in renal inflammation. J Am Soc Nephrol. 2010;21(8):125462. doi: 10.1681/asn.2010020218. 


\section{Correspondence:}

Bin Zang

Department of Critical Care Medicine

Shengjing Hospital of China Medical University

36 Sanhao Street, Shenyang

Liaoning 110004 China

Phone: +86024 9661567111

zangbin_66@163.com

Received: Oct 10, 2019

Reviewed: Dec 13, 2019

Accepted: Jan 16, 2020

\section{Conflict of interest: none}

Financial source: none

This is an Open Access article distributed under the terms of the Creative Commons Attribution License, which permits unrestricted use, distribution, and reproduction in any medium, provided the original work is properly cited.

${ }^{1}$ Research performed at the Scientific Research Center, Shengjing Hospital, China Medical University, China. 